\title{
ORLANDO MASON Y LAS RAÍCES DEL PENSAMIENTO SOCIAL DE PABLO NERUDA
}

\author{
Daniel E. Colón \\ Catholic University of America \\ colon@cua.edu
}

RESUMEN / ABSTRACT

La teoría de la conversión poética y política de Pablo Neruda durante la Guerra Civil española sugiere que la poesía del Premio Nobel chileno antes de este evento carecía de significación política, mientras que su poesía posterior fue orientada por una ideología marxista. En este artículo exploro el desarrollo de la temprana consciencia social de Neruda en su poesía y prosa escritas antes de la publicación de Crepusculario en 1923. El término que empleo para caracterizar sus creencias políticas es "la justicia social," y le presto atención especial al papel del tío de Neruda, Orlando Mason, en su formación.

Palabras clave: justicia social, Orlando Mason, producción literaria temprana de Neruda, teoría de conversión, poesía autobiográfica.

The theory of Pablo Neruda's poetic and political conversion during the Spanish Civil War suggests that the poetry of the Chilean Nobel Laureate prior to this event was devoid of any political significance, while his subsequent poetry was oriented by his Marxist ideology. In this article I explore the development of Neruda's early social consciousness in his poetry and prose written prior to the publication of Crepusculario in 1923. The term I use to characterize his political beliefs is "social justice," and I pay special attention to the role of Neruda's uncle Orlando Mason in his formation.

KEY WORDS: Social justice, Orlando Mason, Neruda's early literary production, conversion theory, autobiographical poetry. 
Según las tendencias en la crítica nerudiana, los pronunciamientos hechos por el poeta en poemas como "Explico algunas cosas" y "Reunión bajo nuevas banderas," que forman parte de la Tercera residencia (1934-1945), sirven para fundamentar la teoría de la conversión política y poética de Neruda durante la Guerra Civil española. Esta teoría propone que Neruda, a partir de su experiencia en España, demuestra un compromiso político previamente ausente y, también, que su nueva visión política se rige por la ideología marxista. Por lo tanto, la poesía que escribe Neruda antes de España se caracteriza por su temática metafísica, romántica y vanguardista, mientras su poesía posterior se destaca por su carácter político. Entre los principales proponentes de esta teoría se encuentran Amado Alonso y Mario Rodríguez Fernández1. En su estudio de 1964, “'Reunión bajo las nuevas banderas' o de la conversión poética de Pablo Neruda", Rodríguez articula de manera sistemática esta teoría:

La tercera Residencia en la Tierra, compuesta por poemas escritos entre el año 1935 y 1945, contiene una composición que nos permite fijar el límite preciso en que se produce un grave y profundo cambio en la índole poética de Pablo Neruda. "Reunión bajo las nuevas banderas" se titula este poema. En él se proclama un nuevo y diferente modo de estar puesto en el mundo. El hablante lírico se hace cargo de una imagen de sí mismo hasta ahora ignorada, oculta, y, sin embargo, sentida como la más propia (185-86).

Aunque uno esté o no de acuerdo con el argumento de Rodríguez Fernández a favor de la conversión, lo importante es que, en términos generales, sugiere un método de análisis esencial para la obra literaria de Neruda: el análisis autobiográfico. La teoría de la conversión política y poética presupone -correctamente, desde mi perspectiva- un vínculo fundamental entre la vida y la obra de Pablo Neruda. Sin embargo, los que se adhieren a esta interpretación entienden el vínculo en términos de una correspondencia

${ }^{1}$ Debo advertir que algunos críticos como Nelson Osorio, por ejemplo, nunca aceptaron la plausibilidad de la teoría de la conversión, sin embargo, nunca se dedicaron a criticarla sistemáticamente tampoco. En su estudio sobre la tendencia de Neruda de emprender varios proyectos de libro simultáneamente, Osorio argumenta que mantener una noción lineal de su producción "son los polvos que traen lodos como los de 'ruptura' o 'conversión poética', de que se suele abusar en la crítica nerudiana" (244). Así, los comentarios de Osorio no van más allá de una crítica soslayada. 
exacta; o sea, lo que Neruda escribe en su poesía es un recuento fidedigno de lo que pasa en su vida.

Por lo general, el estudio de la poesía nerudiana siempre ha consistido en vincular el discurso poético con la vida del poeta. Sin embargo, el problema surge cuando la exégesis no toma suficientemente en cuenta que la labor poética necesariamente distancie la realidad de su representación poética. Alain Sicard, en su artículo "El rostro como máscara: Autobiografía e historia en la obra de Pablo Neruda" (1987), destaca la gran falta de un análisis autobiográfico de la poesía de Neruda que supere una simple correspondencia referencial de palabras y hechos. El juego autobiográfico del poeta "[e]s lo que la crítica nerudiana -y en ella me incluyo autocríticamente [dice Sicard] no ha tenido suficientemente en cuenta. Mi propósito es dar un paso tímido en esa dirección" (27). En otras palabras, Sicard argumenta que el lenguaje autobiográfico nunca llegará a reflejar de manera fidedigna los sucesos de la vida externa al texto. Por esta razón no se puede confiar ciegamente en la palabra poética de Neruda.

Un importante precedente para cuestionar la teoría de la conversión en España es el artículo "El problema de la conversión poética en la obra de Pablo Neruda" (2003), de Federico Schopf. En él, Schopf refuta la idea de dividir la obra de Neruda en un antes y un después de España. Sin embargo, lo hace de manera inversa a lo que propongo yo. Es decir, mientras en el presente estudio me dedico a trazar el desarrollo del pensamiento social de Neruda en su vida y obra previa a su experiencia en España durante la Guerra Civil, Schopf destaca las manifestaciones de la poesía metafísica después de la Guerra de España cuando, según la teoría, debería ser solo poesía política:

Individuo y ser social no se sustituyen absolutamente, no se resuelven o integran totalmente el uno en el otro, no se separan del todo, quedando el uno atrás en el tiempo o restando como un lamentable residuo, sino que más bien se superponen, se recubren parcialmente, esto es, las angustias y anhelos del sujeto individual -a pesar de la decisión del poeta de identificarse solo o esencialmente con su dimensión social- continúan existiendo subterráneamente, presionan la superficie en apariencia continua de la escritura nerudiana de este período y suelen aflorar perturbando su aparente coherencia, abriendo brechas en el discurso de la voluntad totalizadora (58).

La coexistencia de diferentes vertientes temáticas dentro de la poesía nerudiana no es solo característica de su obra después de la experiencia en España, sino 
antes también. La veta clave de su obra temprana que no se ha estudiado con suficiente atención es el compromiso social, lo cual denomino como un sentimiento de justicia social. La manifestación de la justicia social en la obra nerudiana se caracteriza por la empatía que demuestra hacia sujetos marginalizados -especialmente por su dolor y sufrimiento-, la denuncia de abusos cometidos por los que se encuentran en posiciones de poder y el énfasis en la acción para corregir las injusticias. En otras palabras, vemos que el mundo literario que crea Neruda está poblado de gente que sufre injusticias y el poeta utiliza su escritura como medio para mostrar empatía con ellos, hacer pública su situación y castigar figurativamente a los responsables.

$$
* * *
$$

Muchos de los textos juveniles de Neruda previos a la publicación de su primer libro, Crepusculario (1923), han recibido relativamente poca atención crítica. Por lo general han sido recopilados en ediciones con comentarios introductorios sobre el contexto general de su redacción pero sin mayor análisis literario ${ }^{2}$. Pese a esta omisión general, estos textos son valiosos y sirven para destacar la justicia social como un aspecto fundamental de la vida y obra temprana de Neruda. Es decir, cambian fundamentalmente la noción existente de la formación personal y desarrollo político de Neruda, y a través de su estudio tendremos una visión nueva y más completa del pensamiento y personalidad de este gran poeta.

Dentro de este contexto, resulta demasiado tajante la conclusión de Hernán Loyola de que: "El valor de los cuadernos, como se puede presumir, es más documental que literario". Continúa:

Ellos permiten al lector y al investigador interesados una rara experiencia: la de asomarse al "taller" de un niño lanzado a la conquista de su lengua poética y seguir sus esfuerzos, vaivenes, vacilaciones,

2 Siete años después de la muerte de Neruda, Matilde Urrutia, su viuda, y Jorge Edwards prepararon un grupo de estos textos para la editorial Seix Barral bajo el nombre: El río invisible: Poesía y prosa de juventud (1980). Posteriormente, se publican Retrato de familia: Neruda 1904-1920 (1996), Cuadernos de Temuco 1919-1920 (1997), Obras completas, 5 vols. (1999), todos con diferentes selecciones de prosas y poemas tempranos de Neruda. Una excepción a esta falta de atención crítica la ofrece Hernán Loyola, quien editó la última edición de las Obras completas. En estudios anteriores como en "Los modos de autorreferencia en la obra de Pablo Neruda" (1964), Ser y morir en Pablo Neruda (1967) y, más recientemente, en Neruda. La biografía literaria (2006), Loyola examina una pequeña selección de poemas que prefiguran los motivos románticos de los primeros libros de Neruda. 
cambios de estilo o de tono, y en particular sus ingenuas tentativas de innovación léxica (incluyen una buena cantidad de "neologismos") (Obras completas IV, 10)

Al contrario de lo que afirma Loyola, el lujo de poder acceder al "taller" del joven Neruda no puede ser sino de valor literario justamente porque permite descubrir el proceso de formación y el pensamiento que informan su producción posterior. De hecho, entender las fuentes no-marxistas de su pensamiento social cambia nuestra perspectiva sobre obras como el Canto general (1950).

En este artículo analizo la producción más temprana de Neruda, escrita a partir de 1917, y recolectada de varios cuadernos juveniles para la edición más reciente de sus Obras completas ${ }^{3}$. La mayoría del contenido de sus cuadernos escolares quedó sin publicar, aunque algunos poemas y artículos breves aparecieron en revistas o diarios, como La Mañana de Temuco. El dueño de La Mañana, diario donde Neruda publicó por primera vez, era Orlando Mason, un pariente cercano ${ }^{4}$, y la relación entre ellos era sumamente importante en cuanto al desarrollo del tema de la justicia social en su formación temprana.

3 En los tomos IV y V de las Obras completas (1999), Hernán Loyola recopila los escritos de Neruda que no figuran en su obra canónica, o sea, "los libros reconocidos por el poeta" (Obras completas IV, 9). El primer conjunto de escritos es una colección de tres cuadernos escolares que colectivamente llevan el nombre Los cuadernos de Neftali Reyes, y cubren los años 1918-1920. Este periodo cubre íntegramente sus años en el sur de Chile. Su siguiente colección, Un hombre anda bajo la luna, reúne escritos de 1919-1922, lo que resulta en una coincidencia de un año con Los cuadernos de Neftali Reyes. Ya que Neruda se muda a Santiago en marzo de 1921, esta segunda colección incluye escritos tanto del sur de Chile como de la capital. Además, estas dos colecciones contienen publicaciones de una variedad de diarios y revistas de ambas regiones, porque antes de viajar a Santiago, Neruda manda poemas a revistas de la capital, como Corre-Vuela, y después de 1921 sigue publicando en La Mañana de Temuco. También es importante notar la advertencia de Loyola con respecto a las fechas que acompañan los poemas y prosas recopilados en las Obras completas de Neruda: "Advertencia. Las fechas de composición que aparecen al pie de algunos poemas son de Neftalí. Por mi parte he agregado respecto a algunos poemas, cuando los conocía, los datos de sus (primeras) publicaciones en periódicos o revistas. Pero sea claro que los textos mismos están tomados de los Cuadernos y no de esas publicaciones" (Obras completas IV, 1217).

4 Sobre el parentesco entre Neruda y Orlando Mason, el poeta típicamente se refería a él como tío, según era costumbre llamar a personas mayores cuya relación familiar exacta no era muy clara. En Neruda: retrato de familia, Bernardo Reyes afirma que es hermanastro sin mayores explicaciones. Hernán Loyola traza de manera mucho más minuciosa los enredos familiares de los Reyes-Mason-Candia-Marverde en Neruda. La biografia literaria (2006), pp. 19-54. Aquí yo me referiré a Mason como tío para ser fiel al discurso autobiográfico de Neruda. 
Entre las características más sobresalientes de la poesía y prosas tempranas de Neruda son los temas del dolor y de descripciones altamente sensoriales que emergen del contacto del poeta con el mundo cotidiano. En su producción temprana la repetición incansable de la palabra dolor le ofrece al lector una muestra de las preocupaciones principales del joven poeta y, al mismo tiempo, señala las limitaciones de su expresión poética. En aproximadamente 180 poemas $^{5}$ que componen el segundo y más cuantioso cuaderno de los Cuadernos de Neftalí Reyes, Neruda emplea la palabra dolor -o alguna variante, como duele, doloroso o doliente- por lo menos una vez en 102 poemas; o sea, en casi el 57 por ciento de los poemas. En algunos casos, como "Comunión ideal," de mediados de 1919, se utiliza un total de seis veces y tres veces en una sola estrofa. De los restantes poemas que no contienen ninguna forma de la palabra dolor per se se utilizan otras palabras como muerte, tristeza, soledad, humilde, cansancio o agonía para producir un efecto similar: eso es, explorar los límites de la condición humana a través de la palabra poética. Sin embargo, el resultado no es una visión tan limitada como a primera vista. De lo contrario, el dolor se explora a través de una variedad de facetas que incluyen el dolor existencial proveniente de la soledad, el dolor de la pobreza, y el dolor que produce el amor ${ }^{6}$. A través de esta aproximación multifacética, Neruda explora tanto el dolor propio como el dolor ajeno, y hasta el dolor de la naturaleza personificada ${ }^{7}$.

5 Hernán Loyola escribe en "Los modos de autorreferencia en la obra de Pablo Neruda" que son más de 160. Hay numerosos poemas que llevan varios números romanos (generalmente tres), que se pueden considerar o como un poema con varias partes o como varios poemas bajo un título común.

6 De estas tres fuentes de dolor, la que no exploraré en mayor profundidad es el dolor que produce el amor. Vale la pena mencionar en esta nota el poema "El dolor del viajero", publicado en Corre-Vuela el 20 de agosto de 1919. Este soneto lleva la siguiente dedicatoria como epígrafe: "A la desconocida que una tarde alumbró la aridez de mi camino con la luz suave de sus ojos verdes" (Obras completas IV, 62). El hablante lírico destaca la contradicción entre el placer de viajar por conocer, en este caso a la joven de ojos verdes, y el dolor de tener que dejar a personas o cosas atrás por la obligación de seguir el viaje. El viaje se vuelve un motivo frecuente con dos implicaciones. Por un lado, es una manera de conocer el mundo, y se hace presente en libros como Residencia en la tierra y Canto general, entre otros. Por otro lado, es una de las maneras como Neruda concibe el paso del tiempo. Sin embargo, esta noción temporal se sustituye luego por un concepto cíclico.

7 Al igual que el dolor del amor, no analizaré en detalle el dolor de la naturaleza. Por lo tanto, dedico algunas breves líneas aquí para explicar un poema ejemplar. "Los álamos" ( $\sin$ fecha, pero probablemente del año 1919); es un grupo de tres sonetos con los siguientes 
Con el dolor como elemento central, Neruda utiliza sus sentidos como medios para llegar a conocer el dolor en sus variadas formas. Los dos sentidos predominantes son la vista y el tacto. De esta forma, Neruda se muestra como un poeta profundamente sensorial desde sus primeros poemas y así se cimienta la veta autobiográfica en su obra ${ }^{8}$. En este sentido, de la misma manera que se repite la palabra dolor, hay un énfasis desproporcionado en las palabras ojos, pupilas y en el tema de la ceguera, como es evidente por los títulos de poemas como "Mis ojos" y otros sobre ciegos. Para Neruda, la vista es la manera principal de percibir el mundo a su alrededor. Luego, agrega el tacto. A través de las manos se establece una relación sensorial que permite un conocimiento profundo del mundo y de las personas. Además, para el otro de la poesía nerudiana, es en las manos donde se demuestra su condición de trabajador y se exhiben los signos de la acumulación de años de trabajo manual. Estos dos sentidos - la vista y el tacto- tienen tanta primacía para Neruda que incluso se exploran de manera simultánea en el poema "Manos de ciego," que es parte de su "Elogio de las manos", junto con "Manos de campesino" y "Manos de tísico".

Esta cualidad sensorial de los poemas de Neruda es la manera principal como demuestra empatía con las personas a su alrededor. Por lo tanto, aunque el enfoque de su poesía oscila entre el dolor propio y "el dolor de los otros" (también el título de una crónica publicada en Claridad en 1921), la dicotomía entre la soledad y el compromiso con el mundo no se presenta como un conflicto. Estos dos polos representan una contradicción que no es

subtítulos: "Luna," "La rebeldía” y "El solitario". En el primer soneto se describe el dolor que sienten los árboles de no poder luchar en contra de su condición terrestre y volar como los pájaros. El segundo soneto sitúa a los árboles en la dura intemperie y recuenta su "lucha salvaje con la naturaleza", que al final resulta inútil porque "serán siempre los eternos vencidos" (Obras completas IV, 72). Finalmente, el último soneto describe a un álamo triste y solitario en el patio de una escuela pobre. En conclusión, este conjunto de poemas, a través de la personificación de los árboles, funciona como una metáfora del deseo de los indefensos de rebelarse en contra de la posición social que les fue designada arbitrariamente.

8 En una conversación con Bernardo Reyes, el sobrino-nieto de Neruda y archivista de la familia, me insistió en esta característica de la poesía nerudiana. Me dio el ejemplo de España: "Neruda probablemente vio sangre y hasta pisó sesos humanos en las calles de Madrid. Luego, en su poesía esto se transforma en sangre corriendo por las calles". Con esta observación de Reyes se entiende aun mejor el argumento de Sicard de que "Esta sangre [de 'Explico algunas cosas'] no corre según las leyes de la naturaleza - o de la historia-sino según las leyes de la escritura" (27). 
necesario resolver. En su presentación en el "Coloquio Internacional sobre Pablo Neruda: (La obra posterior al Canto general)" de la Universidad de Poitiers, Jaime Concha hace hincapié en este mismo punto. Basándose en argumentos de Georg Lukács y Alain Sicard, Concha destaca la paradoja de la soledad como medio para llegar a la conciencia histórica en la poesía nerudiana posterior al Canto general (63-70). De manera similar, Nelson Osorio analiza dos conceptos aparentemente contradictorios que terminan sustentándose mutuamente. Él propone que la pasión amorosa ayuda a Neruda a llegar a un mejor entendimiento de la pasión cívica en Los versos del capitán (1952) y Las uvas y el viento (1954) (240). Ambos artículos se tratan de obras posteriores al Canto general, o sea, posterior a 1950, pero, por mi parte, veo el germen de estas interpretaciones en su obra temprana, debido al rango de emociones por las cuales pasa el sujeto nerudiano a lo largo de la poesía de sus Cuadernos. Es natural que en sus primeras obras Neruda no pueda expresar y sintetizar la soledad y la solidaridad como lo hace en su madurez. Sin embargo, es posible -y muy útil- rastrear la tensión entre ambas tendencias de su obra literaria a través de los años. En este sentido, tras analizar las referencias que hace Neruda a su infancia en el poema "Oda al violín de California," Concha llega a la conclusión de que: "Sí, en el fondo de la soledad Neruda descubre no sólo a la compañía humana (lo cual es una tautología), sino un tropismo de utilidad pública; en su extrema orfandad, el poeta funda su mejor capacidad de apertura social" (70).

$$
* * *
$$

Desde su primera publicación, el compromiso social de Pablo Neruda, todavía conocido como Neftalí Reyes, se pone claramente de manifiesto. A pocos días de haber cumplido apenas trece años aparece su primer artículo, el 18 de julio de 1917 en el diario La Mañana de Temuco. Es un texto breve titulado "Entusiasmo y perseverancia", en el cual Neruda expresa su preocupación por cuestiones sociales y el progreso de la humanidad.

Neruda comienza su artículo afirmando: "Estos dos [el entusiasmo y la perseverancia] son los factores que coadyuvan principalmente al levantamiento y engrandecimiento de los pueblos". En el primer enunciado, al mismo tiempo que hay una postura marcadamente comprometida, se hace evidente también un concepto general, o hasta ambiguo, del objeto de su compromiso: los pueblos. La noción abstracta de Neruda es más evidente en los siguientes párrafos con el uso de términos como "países," "clases obreras" y "humanidad". Esta manera de manifestar sus inquietudes juveniles demuestra una formulación apenas rudimentaria de su sensibilidad social. Su 
tendencia a generalizar también se ve cuando Neruda quiere expresar lo que su concepción de justicia les ofrecería a los pueblos de diferentes países. Al comienzo de su artículo, Neruda emplea la frase "engrandecimiento de los pueblos," y más adelante argumenta que el entusiasmo y la perseverancia "aportarían bienes en abundancia", además de traer "grandes beneficios a la humanidad" (Obras completas IV, 49, énfasis mío). A través de frases de este tipo, tanto el objeto de su compromiso como los valores que informan su noción de justicia recurren a lo abstracto. Con el tiempo se afina su concepto de quiénes son el objeto de su compromiso social y también quiénes son los que perpetúan las injusticias. Pero a esta temprana edad, la falta de contacto directo con las luchas sociales impide una manifestación poética más concreta. Por lo tanto, se podría clasificar su compromiso como indirecto, o sea, una observación que viene a través del filtro de las palabras y experiencias de terceros. La fuente principal de estas ideas es su tío Orlando Mason, director del diario La Mañana.

Antes de examinar la contribución de Mason a la temprana formación de Neruda, quiero destacar otro elemento de suma importancia en esta primera manifestación escrita de sus sentimientos de justicia social. El título de este artículo -"Entusiasmo y perseverancia"-revela mucho sobre el pensamiento del joven Neruda, porque ambos términos sugieren la necesidad de actuar para efectuar cambios positivos en la vida de la gente. La acción es un elemento básico y constante a lo largo de su vida y obra. Mientras las metas y el objeto de su acción necesitan más desarrollo dentro de su escritura, el énfasis en la acción como elemento fundamental de su pensamiento es prominente desde el principio. Más aún, Neruda hace una conexión importante entre la labor intelectual y la acción social: "Hay filósofos en el siglo presente que sólo tratan de difundir el entusiasmo y la perseverancia y sus libros son verdades sinceras y elocuentes, que leídas por todos, en especial por las clases obreras, traerían grandes beneficios a la humanidad" (Obras completas IV, 49). Para Neruda no basta solamente quedarse en la contemplación filosófica, sino que el fin implícito de este tipo de reflexión intelectual debe ser mejorar las vidas poniendo en práctica sus convicciones.

En un discurso del año 1954, "Infancia y poesía," con ocasión de sus cincuenta años, y que veinte años después fuera recogido parcialmente en sus memorias, Confieso que he vivido, Neruda rememora los momentos más importantes de su juventud en el Chile austral. Tras narrar su experiencia de iniciación cuando toma una copa de sangre de un cordero recién degollado, Neruda recuerda: 
Entre esta gente violenta apareció un hombre romántico que tuvo mucha influencia sobre mí: Orlando Mason. Fue el primer luchador social que conocí. Fundó un diario. Allí se publicaron mis primeros versos y allí tomé el olor a la imprenta, conocí a los cajistas, me manché las manos con tinta. Este hombre hacía violentísimas campañas contra los abusos de los poderosos. ...

Orlando Mason protestaba por todo. Era hermoso ver ese diario entre gente tan bárbara y violenta defendiendo a los justos contra los crueles, a los débiles contra los prepotentes (Obras completas IV, 923)

Mason fue un modelo para Neruda, porque desempeñaba conjuntamente los papeles de poeta y luchador social, y es significativo que estos dos elementos sean los que evoca al recordar al hombre que hizo posible su primera publicación. En su libro Neruda: retrato de familia (1996), basado en documentos y testimonios familiares, Bernardo Reyes describe la personalidad de Mason y la relación con el joven Neruda de la siguiente manera:

Orlando, joven e impetuoso, era un hombre de talento y de iniciativa. En él se conciliaban sabiamente la energía que necesita un hombre de empresa y la sensibilidad, expresada en su reconocido prestigio como declamador y poeta. El diario La Mañana lo había proyectado como una tribuna desde la cual las injusticias inherentes a la situación fundacional de la ciudad de Temuco debían denunciarse, como el bandidaje todavía bastante extendido y el bandidaje solapado que usaba como armas para el despojo de las tierras mapuches a las leyes, los tinterillos y las apariencias de hombres de bien. En las reuniones sociales era habitual requerir de Orlando para su conocido número declamatorio que tenía una alta dosis de teatralización. Neftalí miraba embelesado los recitales de su tío Orlando en casa de familiares. Sí, así quería ser (79).

Reyes llega a la conclusión de que Orlando Mason “fue el hombre más influyente en la formación del pequeño poeta en ciernes” (83). Esta relación enfurecía al autoritario padre de Neruda, José del Carmen Reyes, quien quería para su hijo una formación más tradicional. Mientras el padre de Neruda intenta negarle la carrera de poeta, es notable que "Fuera del tío poeta, nadie parece atribuir ninguna importancia a lo que escribe el aprendiz de adolescente" (Teitelboim 36). A través de esta estrecha relación, Mason se transforma en la fuente que nutre la sensibilidad social que, a esta temprana edad, solo se puede clasificar como embrionaria. 
Antes de que un siniestro acabara con La Mañana, Neruda publicó un total de trece poemas, crónicas y artículos entre el 18 de julio de 1917 y el 10 de septiembre de 1923. No es una cantidad extraordinaria cuando se toman en cuenta los cientos de textos que componen los cuadernos juveniles que mantenía Neruda entre 1918 y 1927 cuando partió para el Oriente como cónsul chileno. Ya que esta producción demuestra un mayor nivel de compromiso social que su producción en otras revistas, como Corre-Vuela de Santiago y Selva Austral de Temuco, se puede concluir que La Mañana le sirvió como el primer foro público para estas ideas -Claridad y Juventud serían otros después de llegar a Santiago como estudiante en marzo de 1921. Es importante recalcar que, en adición a los poemas y prosas de La Mañana, hay otros que son igualmente comprometidos, que están recopilados en sus cuadernos, pero que nunca se publicaron. Finalmente, hay otros poemas de los Cuadernos que no demuestran ningún compromiso social. Algunos de los poemas son relativamente más conocidos como "La canción de la fiesta", porque es con éste que gana el concurso de la fiesta de la primavera de la Federación de Estudiantes de Chile, y "Pantheos", porque es "el más antiguo de los poemas incluidos en Crepusculario (1923)" (Obras completas IV, 1224). Sin embargo, no les prestaré atención a estos últimos porque el objeto de este estudio son los poemas y prosas menos conocidos, en los cuales es posible rastrear la evolución de su pensamiento social en la época previa a la Guerra Civil española.

Tras publicar "Entusiasmo y perseverancia" en 1917, el poema "Mis ojos" aparece como la primera composición del segundo de tres cuadernos que colectivamente se designan como Los cuadernos de Neftalí Reyes, en las Obras completas ${ }^{9}$. En este poema de octubre de 1918, el hablante lírico nerudiano ya se percibe como dotado con el poder de la observación; sin embargo, es un don que lo perturba. El comienzo del poema, "Quisiera que mis ojos fueran duros y fríos," lo demuestra angustiado a causa de su percepción aguda del mundo. Al principio, la angustia lo hace retratarse según los rasgos que no posee porque sus ojos no son duros ni fríos. De esta descripción, el lector puede inferir que es un sujeto sensible que se conmueve fácilmente por lo que pasa a su alrededor. Adicionalmente, el uso del imperfecto del subjuntivo hace de este poema una súplica que se hace el hablante lírico a sí mismo de no comprometerse tanto. Pero no es fácil. Él quisiera que sus ojos:

9 El primer cuaderno no contiene composiciones propias, sino poemas copiados de autores famosos. 
... no vislumbraran los dolores humanos, ni la alegría de vivir.

Tanto las penas como las alegrías lo sobrecogen y es incapaz de encauzar sus emociones. En el último cuarteto hay un sutil cambio de enfoque. Expresa los mismos sentimientos, pero ahora se describen según características propias:

Pero estos ojos míos son cándidos y tristes:

no como yo los quiero ni como deben ser.

Es que a estos ojos míos mi corazón los viste,

y su dolor los hace ver! (Obras completas IV, 55).

El dolor que sus ojos perciben ya no es ajeno, sino propio, y a través de este cambio de enfoque se hace un vínculo afectivo entre el yo lírico y el otro. Sin embargo, es evidente que el sujeto nerudiano todavía no está preparado para aceptar plenamente su don de poeta que lo obliga a ver y cantar lo que ve. Es decir, a pesar de que a sus ojos "su dolor los hace ver," no son como él los quisiera. Como lo señalan Concha y Osorio a través del estudio de obras posteriores a 1950, la reconciliación de las contradicciones interiores tarda años en ocurrir.

Mientras tanto, Neruda busca poéticamente resolver sus inquietudes y canalizar sus emociones. Estas tentativas lo llevan por una amplia gama de emociones, momentos de lucidez y esperanza, y también callejones sin salida. "La desesperación," poema inédito y sin fecha-aunque probablemente proviene de 1919, por las fechas de los poemas anteriores y posteriores en el cuaderno- comienza con el mismo tema de querer cegarse para no sentir dolor:

Se han cerrado mis ojos, Dios mío, ¡y no sé de dolor dónde estoy!

El dolor desorienta al hablante lírico y su reacción natural es tapar la vista como mecanismo de defensa. Los siguientes tres versos subrayan la desesperación a que alude el título:

Es muy tarde. Ya todos se han ido y en el alma me clava cruelmente el dolor. ¿Dónde miro? ¡Mis ojos! ¡Mis ojos! 
¿Y a quién recurre el sujeto poético para salvarse? No es a Dios.

¿A quién llamo, Señor, a quién llamo?

¡Es inútil que te llame a ti! (Obras completas IV, 65)

La falta de fe en la religión para ofrecer respuestas al dolor omnipresente en el mundo también se ve reflejada en otros poemas, como "Los sonetos del diablo," un conjunto de tres sonetos inéditos que llevan la fecha del 23 de agosto de 1919. A diferencia de "La desesperación", los ojos no son suyos, sino ajenos y penetrantes:

Ojos que me miran continuadamente con una mirada de envenenamiento,

vienen lentamente las pupilas frías como un llamamiento de la eterna Nada.

Tras lidiar con las tentaciones del "Dios del Abismo" en los primeros dos sonetos del tríptico, en el tercero el hablante queda resignado ante su poder:

Terrorismos enormes, infantiles y llenos del sabor de dolores hondos, desconocidos, cuando se aprietan todas las ansias de ser buenos en una masa informe de terror y olvido.

Lo malo se hace omnipresente y convierte todo lo bueno en "terror y olvido". Su reacción frente a las fuerzas destructoras del bien es que:

los ojos se cierran ante la dolorosa

visión de ignotos fuegos en que todos se abrasan... (Obras completas IV, 91)

Ahora, los ojos vuelven a ser propios; hasta cierto punto. El constante uso de la voz pasiva implica una falta de control. Por un lado es una victoria del mal, pero por otro es uno de los pasos necesarios en el camino que lo lleva a identificarse con los que sufren. Lo que tenemos aquí es un sujeto perdido y solo, buscando a tientas alguna respuesta, solución o salida.

De la misma manera que hay momentos de desesperación y resignación, también los hay de esperanza. "Caminando," el primer poema que Neruda 
publica en La Mañana $^{10}$ el 27 de febrero de 1919 y que precede los dos poemas que acabo de analizar, demuestra una visión indudablemente positiva. Es notorio que la voz poética nerudiana no se destaca como persona individual, sino parte del colectivo y todos los verbos que se refieren a los personajes del poema se conjugan en el nosotros. Con respecto al grupo de jóvenes, aunque se encuentran "agriados los semblantes de cansancio y dolor," el poema termina en una nota triunfalista:

Y entonces con la calma de las aguas tranquilas veremos renovarse la luz de las pupilas y la sed de ilusiones de nuestro corazón (Obras completas IV, 60).

A través del colectivo mayor, el cansancio y el dolor son el camino a sus sentimientos más profundos y medios para renovar la vista. Así, "Caminando" demuestra una actitud frente a la vida que ha de repetirse periódicamente en su obra poética: la esperanza a pesar del dolor ${ }^{11}$.

A fines de julio del mismo año 1919, Neruda escribe durante su clase de Química ${ }^{12}$ el poema "El poeta que no es burgués ni humilde". El título indica las dos claves para el análisis del poema: primero, es necesario entender la autoconcepción que tiene Neruda de sí mismo, y segundo, la manera en que expresa poéticamente los vaivenes de su ánimo en esta época. La terminología empleada en el título demuestra una rudimentaria conciencia de clase social y, específicamente, una tendencia a alinearse en contra de las clases asentadas. Esta postura es significativa porque en vez de identificarse como proletariado, la relación se define más bien por la empatía con las víctimas de injusticias y la lucha en contra de las clases explotadoras. Se afina esta perspectiva en su poesía más madura como, por ejemplo, cuando se proclama portavoz de los incas en "Alturas de Macchu Picchu".

10 Hay que recordar que su primera publicación, "Entusiasmo y perseverancia", fue una prosa breve y no un poema.

11 Este final esperanzado vuelve a aparecer años más tarde como "una voluntad de sobrevivir" -frase de Hernán Loyola- en Residencia en la tierra, España en el corazón y en el Canto general, entre otras obras. Es decir, a pesar del tono pesimista que se expresa en estas obras, Neruda siempre se muestra esperanzado para un futuro mejor, producto de su propia lucha por la justicia social. Con respecto al Canto general, véase, en particular, los poemas "Voy a vivirme (1949)" y "Termino aquí (1949)" del "Canto XV".

12 Junto con el poema se designan explícitamente la fecha y el lugar de composición: "En clase de Química del 30 de julio de 1919" (Obras completas IV, 82). 
Desde el primer verso de este poema hay un desdoblamiento del sujeto poético al referirse a sí mismo en tercera persona:

Un muchacho que apenas tiene quince años, que hace versos punzado por la amargura, que saboreó las sales del desengaño cuando muchos conocen risa y ternura.

El sujeto a que se refiere la voz lírica es obviamente él mismo. Ahora bien, el hecho de que tome esta perspectiva lírica sirve para dar un efecto dramático al texto. El sujeto "que hace versos punzado por la amargura" se diferencia marcadamente de sus compañeros inocentes que "conocen risa y ternura". Se cree una persona experimentada que ha pasado por las tribulaciones de la vida mientras que los compañeros mantienen una ingenuidad juvenil. Su inocencia no les permite ni a ellos ni a las demás personas del pueblo saber que el muchacho de apenas quince años es poeta:

(Los hombres no han sabido que en él existe el poeta que niño no fue pueril) (Obras completas IV, 81).

Específicamente, y aquí entra el aspecto dramático del soneto, tener el oficio de poeta sin que lo sepan los demás es como un álter ego o como un superhéroe: una identidad o persona oculta (en el sentido dramático) con la cual ejerce poderes especiales. Además, el uso de paréntesis funciona como un aparte y aumenta aún más el efecto de divulgar a unos pocos privilegiados un secreto muy importante. Sintiéndose liberado por esta confesión, el poder de la observación y la experiencia de vida ya no le pesan. Por eso, al igual que en "Caminando," el poema termina con una visión optimista del sujeto y su labor de poeta.

El 26 de septiembre de 1919, Neruda publica "Los minutos sencillos" en el diario La Mañana. Es un conjunto de tres poemas designados con números romanos, cada uno de una extensión de entre diez y doce versos y en verso libre, o sea, sin rima, sin una versificación constante y sin estructura estrófica. Por ejemplo, el primer poema es un solo enunciado sin verbos conjugados - están siempre en el infinitivo y hay un verbo en el gerundio- y comienza in medias res; por su brevedad reproduzco el poema entero: 
Deseo de irse andando por todos lo caminos del mundo, caminos agrestes de verdor y de luz, caminos ciegos de la noche, caminos gloriosos de sol, y esparcirse por todos los caminos, arrastrarse en las sinuosidades del dolor y de la alegría, plenos del deseo lento, claro y sencillo de estar en todas partes, de haber llevado en todos los caminos la miseria escondida de los dolores humanos

(Obras completas IV, 215).

La audacia en la forma representa una ruptura marcada de su producción poética hasta el momento que utiliza excesivamente el soneto. La dependencia de Neruda en una forma poética tradicional es otro ejemplo de la falta de desarrollo de una voz poética propia en sus primeros años, como lo es también la repetición de ciertas palabras como dolor. Es evidente que la tradición poética le pesa tanto al joven Neruda que cuando comienza a publicar sus primeros libros de poesía, a partir de 1923, recurre a modelos tradicionales para ganar aceptación. Refiriéndose a Crepusculario, Jaime Concha señala la predominancia de formas y motivos tradicionales que encajan al libro dentro de una trayectoria poética determinada:

Todavía sus versos están sometidos al imperio de la rima, campana leve que el modernismo conservó por amor a la eufonía; todavía hay en Neruda respeto por el verso medido y por ciertas formas métricas tradicionales. Así, Crepusculario comienza con cuatro sonetos alejandrinos, cultivando una preferencia estrófica también grata a Darío. En "Sensación de olor", la evocación y contemplación interior se producen estimuladas por una impresión sensorial. Todo esto, unido al virtuosismo en los efectos cromáticos, visible, por ejemplo, en el primer soneto ("Esta iglesia no tiene..."), permiten situar legítimamente el poemario en la sensibilidad posmodernista ("Proyección" 10).

En cambio, el uso de verso libre por primera vez en "Los minutos sencillos" es indicativo de la libertad que Mason le concede a Neruda y lo demuestra también como modelo iconoclasta para el joven poeta. Es de notar que ni siquiera en sus poemas no publicados en estos cuadernos hay un ejemplo anterior de verso libre. 
Con respecto al contenido, los tres poemas del conjunto tratan, respectivamente, el dolor humano, la naturaleza, y la noche. En el primer poema (citado arriba), la voz lírica nerudiana ya empieza a mostrarse más dispuesta a aceptar la carga del dolor de los otros en su papel de poeta. En el segundo, se presenta la naturaleza como una fuerza sumamente poderosa, capaz de cegar a los seres humanos:

\section{...Y los ojos lo miran todo, lo abrazan todo, árboles y cosas, \\ ciegos y humildes en la consagración misma del minuto agreste (Obras completas IV, 215).}

Finalmente, en el último poema la noche, en su función de musa poética, hace más transparentes y tangibles las emociones y dolores humanos. La luna ilumina el camino que emprenden el hablante lírico y su amigo: "Yo y mi amigo marchamos por el sendero lunado..." (Obras completas IV, 216). El yo nerudiano no se encuentra solo en su camino simbólico como poeta porque tiene el compromiso de enseñarle a su "amigo" -el lector que, a su vez, representa todo el público lector- lo que no es capaz de ver o entender. Por lo tanto, en "Los minutos sencillos" se sintetiza la temática general de su producción hasta el momento y se emplean varios símbolos recurrentes: el dolor, la caminata como medio de conocer el mundo, la ceguera por causa de una abundancia de estímulo sensorial, y la noche como fuente de inspiración.

El 12 y 27 de abril, 1920, Neruda publica una serie de prosas en La Mañana, bajo el título "Las semanas" que tienen mucho en común en términos de estilo y contenido con sus contribuciones posteriores en Claridad y Juventud. Cada número de "Las semanas" contiene tres crónicas que varían en su temática de reseñas de exposiciones de arte a contemplaciones sobre la pobreza y la vida provinciana de Chile. El primer número de "Las semanas" comienza con "Leyendo a Azorín en un pueblo chico". Esta breve prosa tiene apenas un comentario somero sobre su obra: "Enterrados en la quietud de un pueblo muy pequeño, hemos leído a Azorín. Y esto tiene un encanto doble: una página de Azorín es un día de vida de pueblo, vida sencilla y buena, casi buena". El resto del texto está dedicado a llamar la atención a la falta de autocrítica de quienes viven en "pueblos humildes". Neruda utiliza al autor anarquista español como punto de partida e, implícitamente, como un modelo de objetividad. La metáfora que emplea para referirse a la introspección es la del descenso: "Habremos de descender a nosotros mismos si queremos 
descender al alma de los pueblos humildes" (Obras completas IV, 247). Califica a los habitantes de pueblos chicos y humildes como "cobardes" y "débiles", porque prefieren la "burdas alegrías" superficiales a enfrentar la tristeza profunda que reside en el alma del pueblo.

En los otros dos textos del tríptico critica la hipocresía y falta de cultura de la burguesía temuquense. Específicamente, en "Oyarce y su exposición" arremete contra la falta de apoyo que reciben los artistas nacionales frente a los extranjeros:

Oyarce tiene mucho de original. Y por eso, en este pueblo en que ha vivido toda su vida, ha fracasado.

De sus dibujos en que él ponía tanto de su alma fuerte, no se vendió uno solo. Y no es que hayan sido malos. Aquí se han vendido cuadros mamarrachentos de pintores con nombres uruguayos, brasileños, etc. Es que aquí necesitan nombres sonoros, nombres conocidos. $\mathrm{Y}$ esos burgueses que compran cuadros malos, estos burgueses que no ayudan la noble iniciativa de Oyarce porque es de aquí, estos burgueses necesitan taparse con decir: yo compré un cuadro de tal...

Y el cuadro es un mamarracho (Obras completas IV, 248-49).

En "Nada de originalidades" se ofrece una reseña desfavorable de una película "vulgar [que] alaba la raza heroica, los copihues rojos como la sangre, las selvas impenetrables y un cúmulo de vulgaridades más" (Obras completas IV, 249; énfasis original). Se critica la manera en que el cineasta busca justificar una clase social de "gente distinguida" que no hace más que sentarse inútilmente en la plaza. De lo contrario, Neruda interpone:

$\mathrm{Y}$ he pensado en los que en el atardecer trabajan, escriben, leen, en los que huyen para mirar la belleza del crepúsculo lejos de una banda ramplona, sin trajines exhibicionistas, dando más alas a la serenidad de los espíritus, dando más firmeza a la soledad de los sueños. Esta gente, para los dueños de la película, esa gente que piensa, que trabaja, ésa no es la gente distinguida..." (Obras completas IV, 249).

A través de estas tres crónicas, Neruda demuestra una fuerte postura en contra de la clase burguesa, como era evidente en "El poeta que no es burgués ni humilde". Reitero que la postura de Neruda es la de estar en contra, siempre oponiéndose a una clase social o política que permite o promueve injusticias. Más aún, no se identifica como oprimido, sino que demuestra empatía por su dolor. Además, es importante subrayar que es en el diario de su tío Orlando 
Mason donde experimenta con nuevas formas de expresión, como la crónica, y agudiza su particular visión social.

En el segundo grupo de crónicas, publicado dos semanas después y que lleva el mismo título, Neruda demuestra la misma actitud crítica frente a la vida provinciana. La primera de las tres, "Calle arriba y calle abajo," recurre al frecuente motivo de la caminata para conocer la vida: "Hay que andar calle arriba, calle abajo por estas calles llenas de barro, llenas de miseria para saber la tristeza de este pueblo" (Obras completas IV, 249-50). Tras una descripción de la "desolación" que caracteriza a los habitantes en el gris invierno austral, hay una directa apelación a que el lector también demuestre empatía por los pobres y desamparados: "Oh! cómo odiamos, cómo odias tú, lector joven y fuerte que lees estas líneas, a esa gente indiferente y egoísta que no mira los dolores de nadie, que se escurre venenosamente bajo sus paraguas enlutados, mientras la rabia del invierno se deshace en aguas..." En el segundo texto, "Los árboles", le presenta al lector un contraste directo a la insensatez humana de la crónica anterior. Mientras el narrador califica al lector como indiferente a los dolores humanos, los árboles representan amistad y compasión incondicionales para el viajero cansado. Recalcando aún más la oposición entre hombre y naturaleza, termina con una pregunta reflexiva: "Son pasivos y buenos estos árboles amarillos de otoño, heridos de bronce y de sol, no es cierto?" (Obras completas IV, 250). La última crónica del grupo, "Un recuerdo de "Selva Austral": E. Silva Román", se asemeja mucho en términos de tema y tono a "Oyarce y su exposición" y "Nada de originalidades" de "Las semanas" [I]. Alaba el espíritu del joven poeta Ernesto Silva Román por aventurarse a fundar y mantener viva una muy original revista literaria en Temuco, que tuvo contribuciones de Gabriela Mistral, entre otros, y reprocha la actitud hipócrita de quienes la censuraron por razones de "moralidad" y "honestidad" (Obras completas IV, 251).

El poema "Las manos de los ciegos," escrito el día de su cumpleaños (12 de julio de 1920) se incluye más tarde en el tríptico de sonetos "Elogio de las manos", junto con "Manos de campesino" y "Manos de tísico", publicado en Selva Austral, número 3, Temuco, 1920. Los sonetos presentan motivos poéticos muy importantes en el desarrollo de Neruda: las manos, la ceguera y los trabajadores. En "Las manos de los ciegos", el sujeto nerudiano compadece a un hombre ciego y le implora en el primer verso: "Dame tus manos, ciego". Como el ciego no puede ver -y así queda en oposición directa con el sujeto de "Mis ojos" que ve demasiado- utiliza las manos como medio para conocer el mundo a su alrededor. El hablante lírico valora el poder que hay en las manos 
de los ciegos porque "son como las raíces... y en el otoño sienten cómo llega la Muerte... Los ciegos tienen toda su alma en estas manos". Tomando en cuenta estas características de las manos de los ciegos, la súplica del primer verso asume un aspecto casi sagrado: quiere sentir con sus manos, las manos del hombre que lo presiente, pero que no lo ve. Quiere, como a través de la osmosis, sentir lo que el otro siente y aprender de él. La última estrofa del poema presenta una característica más de estas manos sagradas: "parecen dos santas palomas de milagro / tajeadas y sangrantes de noche y de dolor!" (Obras completas IV, 159). La imagen de la paloma en la obra nerudiana es símbolo de la perfección poética, y contrasta marcadamente con la elegancia del cisne modernista. Ésta es la primera vez que aparece este símbolo y su uso destaca el valor que ve el sujeto poético en este arquetipo de personaje marginal de la sociedad.

Las "Manos de campesino" son buenas, honradas y también santificadas. Como hemos visto en otros poemas, la religión no ocupa un lugar privilegiado y es, más bien, desprestigiada por su inhabilidad de ofrecer soluciones a los problemas existenciales de Neruda. En este caso, al igual que con la paloma sagrada de "Las manos de los ciegos", el uso de la terminología religiosa le concede un valor significativo a lo cotidiano, más que resaltar aspectos positivos de la religión. Aquí lo cotidiano se refiere a la labor campesina y la siembra "que nos dan el trigo rubio y el pan de cada día". Sin embargo, las manos titulares del campesino nunca reciben el reconocimiento que merecen:

Debieran de llenarlas de las perlas y de gemas:

manos de campesino que son como poemas

en que los versos huelen a tierra y a sudor! (Obras completas IV, 166).

Con el fin de valorar el trabajo que otros desestiman, el sujeto lírico lo compara con su propio oficio de poeta, el máximo elogio posible desde su punto de vista.

"Manos de tísico" nos ofrece una perspectiva similar a los otros dos sonetos en el tríptico, con la diferencia de tratar un personaje aún más marginalizado en la sociedad. El tísico está enfermo, al igual que un ciego, pero la ceguera no se contagia como la tuberculosis. Por eso estas manos "han sentido la huida de las almas ardientes / lejanas compañeras de sus 18 abriles". A pesar de ser buenas y "austeramente santas en su triste virtud", las manos de esta persona parecen no conocer el tacto de otros seres, sino solamente su "huida" (Obras completas IV, 167). 
Una última observación sobre este poema trata de la frase "sus 18 abriles". Al referirse a la edad de esta persona, Neruda sugiere que es una persona conocida; sin embargo, averiguar su identidad, como otros críticos han hecho en circunstancias similares para "explicar" versos o poemas de Neruda, sería un acercamiento descaminado e infructuoso. De lo contrario, el valor de entender las raíces autobiográficas de este poema radica en entender cómo Neruda es capaz de poetizar a personas o hechos de su experiencia vital y hacerlos universales para sus lectores. De hecho, no importa, en realidad, si este adolescente es enfermo de tuberculosis o cualquier otra enfermedad comunicable. Lo importante es apreciar la empatía que demuestra la voz lírica por esta persona enferma y concederle la dignidad que merece.

Esta primera muestra (no exhaustiva) de textos juveniles, lejos de presentarnos un poeta preocupado únicamente por temas del amor, de la naturaleza o de la soledad, nos lo presenta seriamente comprometido con el mundo en su dimensión social. Contempla profundamente su propio estado existencial vis-à-vis el otro. A pesar de su enfoque altamente personal, el sujeto nerudiano nunca se encuentra enajenado o ensimismado hasta el punto que pierde el sentido social de su oficio como poeta. Busca entender a través de sus sentidos y su poesía los dolores que sienten los demás. Entiende que son producto de las injusticias enraizadas en la sociedad chilena -y específicamente en la ciudad de Temuco-y se muestra preocupado en un nivel básico por la pobreza, las personas más marginalizadas y su propia relación con ellos. El papel de Orlando Mason aquí es fundamental. Es un modelo de luchador y poeta, y también le facilita un foro público para experimentar poéticamente y expresar sus convicciones sociales. Claramente, el pensamiento social de Pablo Neruda se arraiga en la relación con su tío; sin embargo, necesita muchos años más para madurar adecuadamente.

En marzo de 1921, Neruda se traslada a Santiago para estudiar francés en el Pedagógico de la Universidad de Chile. Se incorpora con facilidad al ambiente estudiantil de la capital, hace amigos importantes a través de la Federación de Estudiantes de Chile (FECh), y participa activamente en las revistas Claridad y Juventud. En estas revistas, Neruda publica algunos de sus textos más comprometidos, como las series "Glosas de la ciudad" y "Glosas de la provincia". Este nuevo entorno le brinda al poeta un contacto más directo con las luchas sociales, y por eso, paulatinamente, es capaz de poetizar su pensamiento social con mayor precisión y de manera cada vez más sofisticada. Más aún, cada etapa de la vida de Neruda representa, progresivamente, un mayor involucramiento personal en la vida política, lo 
cual se ve reflejado en su poesía. Durante su juventud en el sur, solo observa a su tío Orlando Mason, como estudiante en Santiago marcha en las protestas, en el Oriente es testigo directo del colonialismo, en España organiza conferencias y lidera organizaciones internacionales antifascistas, y como senador de la República de Chile es sujeto de una persecución personal por sus convicciones democráticas y humanitarias. A lo largo de este proceso, la expresión poética de su pensamiento social evoluciona de una dependencia en términos vagos como "dolor," "engrandecimiento de los pueblos" y "beneficios [para] la humanidad", hasta utilizar nombres en su poesía -como Franco y Mola, en España en el corazón, o cualquier otro nombre de la letanía de personajes históricos que aparecen en el Canto general-para referirse a los responsables y también a las víctimas de injusticias.

Con respecto a la particular visión social expresada en el Canto general, Ángel Rama, en "Pablo Neruda: El retorno del Conde de Montecristo" (1974), destaca cómo Neruda interioriza conflictos ajenos en su poesía: "Ahora nos es claro que el furor vindicativo del Canto general es, evidentemente, hirsuta rebelión de la conciencia moral, pero también que lo enciende una subjetividad que gusta trasmutar el conflicto histórico en venganza personal" (II-III). La subjetividad del pensamiento social de Neruda es lo que lo vincula estrechamente a la empresa autobiográfica. Es decir, la postura ético-moral expresada en su obra literaria nace de circunstancias personales, al mismo tiempo que sucesos ajenos se vuelven propios al poetizarlos. Por lo tanto, la justicia social es uno de los aspectos más fundamentales de la poesía autobiográfica del poeta. Finalmente, comparando a Neruda con su homónimo, Picasso, Rama dice:

Ambos hombres hicieron una opción política que de algún modo dio prueba de sus sentimientos de justicia social, de su oposición crítica a la sociedad burguesa en que vivían e incluso contribuyeron con su participación a la credibilidad de una doctrina especialmente resistida en el área hispánica (IV; énfasis mío).

A continuación, Rama señala que la orientación de Neruda hacia la justicia social se destaca por sus "apelaciones a la libertad, al pueblo, al amor humano, a las luchas sociales" (IV). En última instancia, la justicia social es eje central de su obra cumbre, el Canto general, y refleja nuevos matices sobre la visión política en ésta y todas sus obras escritas a partir de la Guerra Civil española, que suelen interpretarse en términos marxistas. Las raíces del pensamiento social de Neruda se extienden a la relación con su tío, Orlando Mason, prefigurando 
su contacto con ideologías marxistas, y esta manera alternativa de entender su formación política nos hace ver sus obras maduras en una nueva luz.

\section{BIBLIOGRAFÍA}

Alonso, Amado. Poesía y estilo de Pablo Neruda. 1940. Madrid: Gredos, 1997.

Concha, Jaime. "Neruda, desde 1952: 'No entendí nunca la lucha sino para que ésta termine"”. Actas del Coloquio Internacional sobre Pablo Neruda (La obra posterior al Canto general). Universidad de Poitiers: CRLA, 1979. 47-78.

"Proyección de Crepusculario". Tres ensayos sobre Pablo Neruda. Hispanic Studies, Number 1. Columbia, S.C.: Dept. of Foreign Languages \& Literatures, University of South Carolina, 1974. 5-30.

Loyola, Hernán. “Introducción”. Residencia en la tierra. Pablo Neruda. Ed. Hernán Loyola. $5^{\text {a }}$ ed. Madrid: Cátedra, 1999. 64-125.

"Los modos de autorreferencia en la obra de Pablo Neruda". Aurora 3-4 (1964):

Neruda. La biografia literaria. Santiago: Editorial Planeta Chilena S. A., 2006.

Neruda, Pablo. Cuadernos de Temuco 1919-1920. Ed. Víctor Farías. Barcelona: Seix Barral, 1997. El río invisible: poesía y prosa de juventud. Barcelona: Seix Barral, 1980.

Obras completas. Ed. Hernán Loyola. 5 Vols. Barcelona: Galaxia Gutenberg, Círculo de lectores, 1999.

Osorio, Nelson. "Contexto real y contexto virtual en Los versos del capitán". Actas del Coloquio Internacional sobre Pablo Neruda (La obra posterior al Canto general). Universidad de Poitiers: CRLA, 1979. 235-59.

Rama, Ángel. "Pablo Neruda: El retorno del Conde de Montecristo". La cultura en México, Suplemento de Siempre! 1109 (25 Sept. 1974). I-VII.

Reyes, Bernardo. Entrevista Personal. 30 diciembre 2008.

Retrato de familia: Neruda 1904-1920. San Juan, PR: Editorial de la Universidad de Puerto Rico, 1996.

Rodríguez Fernández, Mario. “'Reunión bajo las nuevas banderas’ o de la conversión poética de Pablo Neruda". Neruda comentado. Ed. Federico Schopf. Santiago: Editorial Sudamericana, 2003. 185-203.

Schopf, Federico. "El problema de la conversión poética en la obra de Pablo Neruda". Atenea: Revista de Ciencia, Arte y Literatura de la Universidad de Concepción 488 (verano 2003): 47-78.

Sicard, Alain. "El rostro como máscara: Autobiografía e historia en la obra de Pablo Neruda". Nuevas aproximaciones a Pablo Neruda. Comp. Ángel Flores. México: Fondo de Cultura Económica, 1987. 26-33.

Teitelboim, Volodia. Neruda. $3^{\text {ra }}$ edición. Santiago: Editorial Sudamericana, 2000. 